\title{
Correlations between distribution coefficients of various biomolecules in different polymer/polymer aqueous two-phase systems
}

\author{
Pedro P. Madeira a,b,c,1, José A. Teixeirab ${ }^{\mathrm{b}}$, Eugénia A. Macedo ${ }^{\mathrm{a}, *}$, \\ Larissa M. Mikheeva ${ }^{c}$, Boris Y. Zaslavsky ${ }^{c}$ \\ a LSRE - Laboratory of Separation and Reaction Engineering, Dpt. de Engenharia Química, Faculdade de Engenharia da Universidade do Porto, \\ Rua Dr. Roberto Frias s/n, 4200-465 Porto, Portugal \\ b IBB-Institute for Biotechnology and Bioengineering, Centre for Biological Engineering, Universidade do Minho, \\ Campus de Gualtar 4710-057, Braga, Portugal \\ ${ }^{c}$ Analiza Inc., 3615 Superior Ave., Suite 4407b, Cleveland, OH 44114, USA
}

\section{A R T I C L E I N F O}

\section{Article history:}

Received 29 January 2008

Received in revised form 5 March 2008

Accepted 6 March 2008

Available online 14 March 2008

Keywords:

Aqueous two-phase systems

Protein partitioning

Collander equation

\begin{abstract}
A B S T R A C T
Distribution coefficients for a variety of proteins and certain other biomolecules (peptides, amino acids, and carbohydrates) (overall 27 different solutes) were measured in aqueous two-phase systems (ATPSs) dextran (Dex)-polyethylene glycol (PEG) and Dex-Ucon 50-HB-5100 (Ucon-a random copolymer of ethylene glycol and propylene glycol) both containing $0.15 \mathrm{M} \mathrm{NaCl}$ in $0.01 \mathrm{M}$ phosphate buffer, $\mathrm{pH} 7.4$, at $23^{\circ} \mathrm{C}$. Distribution coefficients of some selected solutes were also measured in the above two-phase systems at three different polymer concentrations for each system. It was established that the distribution coefficients for all the proteins examined in the ATPSs are correlated according to the so-called Collander linear equation.
\end{abstract}

(C) 2008 Elsevier B.V. All rights reserved.

\section{Introduction}

Aqueous two-phase systems arise in aqueous mixtures of different water-soluble polymers or a single polymer and a specific salt. When two certain polymers, e.g., Dex and PEG, are mixed in water above certain concentrations, the mixture separates into two immiscible aqueous phases. There is a clear interfacial boundary separating two distinct aqueous-based phases, each preferentially rich with one of the polymers. The aqueous solvent in both phases was demonstrated to provide media suitable for biological products [1-4]. These systems are unique because each of the phases contains over $80 \%$ water on a molal basis and yet the phases are immiscible and differ in their solvent properties [4,5]. Therefore these systems can be used for differential distribution of solutes and particles.

Extraction in ATPSs has been clearly demonstrated as an efficient method for large-scale recovery and purification of biological products $[1-3,6,7]$. Low cost, high capacity and easy scale-up are

\footnotetext{
* Corresponding author. Tel.: +351 22204 1653; fax: +351 225081449 . E-mail address: eamacedo@fe.up.pt (E.A. Macedo).

1 Permanent address: Laboratory of Separation and Reaction Engineering, Dpt. de Engenharia Química, Faculdade de Engenharia da Universidade do Porto, Rua Dr. Roberto Frias s/n, 4200-465 Porto, Portugal.
}

clear advantages of this technology. Partitioning in ATPSs may also be used as a bioanalytical tool for characterization of protein surface properties [4,8], changes in protein structure [9], conformation [10], ligand binding [1-3], etc. Successful application of partitioning in ATPSs requires understanding of the mechanisms of solute distribution in the systems and properties of the systems at the molecular level.

Understanding of the mechanisms of solute partitioning in ATPSs is important for both separation and bioanalytical applications, though for slightly different reasons. When ATPSs are used for separation purposes it is important to predict optimal extraction conditions for a target product from a particular source and/or to design optimized strategies for the search of such optimal conditions. Thus, understanding of the role of different factors, such as $\mathrm{pH}$, type and concentration of salt additives, type of phase-forming components, etc., affecting distribution of the product and contaminants is much more important from a practical viewpoint than understanding why the product partitions into a certain phase. For analytical applications the comprehension of the partitioning mechanisms is crucial since it defines the information provided by a change in the analyte partition behavior under altered partition conditions or as a response to a change in the analyte properties.

There are essentially two lines of reasoning in the literature, see, e.g. [4] and references cited therein in regard to the mechanisms of solute partitioning in ATPSs. The underlying concept of the first 
one is based on solute interactions with the phase-forming components being the driving force for partitioning, ignoring the specific features of water as a solvent in the coexisting phases. According to the models based on this approach, water is considered as a solvent whose properties are taken into account by coefficients representing deviations from the behavior of ideal solutions defined according to the Lewis-Randall standard state. These models are typically based on the Flory-Huggins theory [11,12], on lattice models, e.g. UNIQUAC $[13,14]$ or on osmotic virial expansion methods [15-18].

The underlying concept for the other line of reasoning is that polymers and salts engaged in formation of an ATPS serve as components that are essentially neutral to the solute being partitioned and are important only in regard to their effects on the solvent features of the aqueous media in the coexisting phases. (It should be mentioned that this concept is clearly inapplicable to the ATPS containing charged polymers or polymers carrying ligands for the so-called affinity partitioning.) This approach is based on the experimental evidence indicating that (a) the solvent features of aqueous media in the coexisting phases of ATPS are different [4,5], and (b) there are clear similarities between partitioning of solutes in ATPS and in water-organic solvent systems [4,5,19-23].

One important distinction of ATPS from organic solvent-water biphasic system is that while a single equilibrium composition exists for any solvent-water system, a variety of quantitatively different compositions exists for an ATPS formed by a given pair of polymers or a single polymer and inorganic salt. One of the important features of organic solvent-water biphasic systems is the linear relationship between the logarithms of the distribution coefficients of solutes of the same chemical nature in different solvent biphasic systems see, e.g., in ([24], pp. 100-103). The applicability of this relationship to ATPSs for the partition of biomolecules was explored earlier with a limited set of systems formed by Dextran and Ficoll or PEG see in ([4], pp. 268-276), and for small organic neutral compounds in systems formed by PEG and various inorganic salts $[5,20]$. It seems reasonable to expect that analysis of relationships between distribution coefficients of various biomolecules in different ATPSs may provide information useful for practical purposes as well as for better insight into the mechanisms of partitioning.

In this work, we examined the distribution coefficients for a variety of proteins and low molecular weight solutes in ATPSs formed by Dex and PEG and by Dex and Ucon, both containing $0.15 \mathrm{M} \mathrm{NaCl}$ in $0.01 \mathrm{M}$ phosphate buffer, $\mathrm{pH}$ 7.4.

\section{Experimental}

\subsection{Materials}

\subsubsection{Polymers}

All polymers were used without further purification. Dextran 75 (lot 115195), $M_{\mathrm{W}} \cong 75,000$ was purchased from USB (Cleveland, $\mathrm{OH}$, USA). Polyethylene glycol 8000 (lot $69 \mathrm{H} 00341$ ), $M_{\mathrm{W}}=8000$ was purchased from Sigma-Aldrich (St. Louis, MO, USA). Ucon 50-HB-5100 (lot SJ1955S3D2), $M_{\mathrm{W}}=3930$ was purchased from Dow-Chemical (Midland, MI, USA).

\subsubsection{Proteins}

Chicken egg lysozyme (\#L-6876), bovine $\alpha$-chymotrypsinogen A (\#C-4879), bovine hemoglobin (\#H-2500), horse heart cytochrome c (\#C-7752), bovine ribonuclease $\mathrm{B}$ (\#R-7884), bovine ribonuclease A (\#R-5000), bovine trypsinogen (\#T-1143), human hemoglobin (\#H-7379), horse myoglobin (\#M-0630), bovine $\beta$-lactoglobulin (\#L-3908), and human $\gamma$-globulin (\#G-4386) were purchased from Sigma. Porcine lipase (\#18480), human transferrin (\#22508), and bovine $\gamma$-globulin (\#16021) were purchased from USB. Numbers in parenthesis denote the catalog ID numbers for the particular products in the corresponding catalogs.

\subsubsection{Amino acids}

Dinitrophenylated (DNP) amino acids-DNP-glycine, DNP-alanine, DNP-norvaline, DNP-norleucine, DNP-DL- $\alpha-$ amino- $n$-octanoic acid, and L-tryptophan were purchased from Sigma. The sodium salts of these DNP-amino acids were prepared by titration.

\subsubsection{Peptides}

Di-tryptophan and tri-tryptophan were purchased from BACHEM Bioscience (King of Prussia, PA, USA).

\subsubsection{Monosaccharides}

Nitrophenylated (NP) monosaccharides-4-NP- $\beta$-D-galactopyranoside, 4-NP- $\beta$-D-fucopyranoside, $4-\mathrm{NP}-\beta$-D-glucopyranoside, and 4-NP- $\alpha$-D-mannopyranoside were purchased from USB. 4-NP$\alpha$-D-glucopyranoside was purchased from Sigma.

\subsubsection{Others}

$o$-Phthaldialdehyde (OPA) reagent solution (complete) was purchased from Sigma. All salts and other chemicals used were of analytical-reagent grade.

\subsection{Methods}

\subsubsection{Phase diagrams}

The systems were prepared by adding appropriate amounts of the aqueous stock $\mathrm{Ca} .42 \%(\mathrm{w} / \mathrm{w})$ Dex-75 solution and $50 \%(\mathrm{w} / \mathrm{w})$ PEG-8000 (or Ucon 50-HB-5100 40\% (w/w)) solution into a $50.0 \mathrm{~mL}$ separatory funnel. Appropriate amounts of $3.0 \mathrm{M} \mathrm{NaCl}$, and $1.0 \mathrm{M}$ sodium phosphate buffer, $\mathrm{pH} 7.4$ were added so as to give the required ionic and polymer composition. Water was finally added to obtain a $25 \mathrm{~g}$ amount of final system. After vigorous mixing the systems were allowed to settle for $24 \mathrm{~h}$ at room temperature $\left(23^{\circ} \mathrm{C}\right)$. Samples from both phases were collected for characterization. A pipette was used to remove the top phase, while the bottom phase was removed through the drain of the separatory funnel.

Chloride was determined by the argentometric method with a relative error $<2.0 \%$. For details see reference ([25] pp. 4-67:4-68) and the total phosphorus by the ascorbic acid method with a relative error $<5.0 \%$. For details see reference ([25] pp. 4-146:4-147). Dextran concentration was obtained by polarimetry (polarimeter AA-1000, Optical Activity, Ramsey, UK). Since Dextran is very hygroscopic, the stock solution concentration was determined gravimetrically following freeze-drying of aliquots of pre-determined weights. Concentrations of PEG and Ucon were assayed by refractive index measurements with a 3T model refractometer (Atago-Tokyo, Japan) taking into consideration contributions of salts and Dex. The refractive index measurements were performed at $25^{\circ} \mathrm{C}$ in a temperature controlled bath (Frigomix S, B. Braun, Melsungen, Germany, with an uncertainty of $0.1^{\circ} \mathrm{C}$ ). The relative uncertainty in polymer concentration determination was $<5 \%$. All gravimetric measurements were performed with Adam Equipment analytical balance model "AAA 250L" with a $0.2 \mathrm{mg}$ uncertainty.

\subsubsection{Partitioning}

2.2.2.1. Phase systems. A mixture of polymers was prepared by dispensing appropriate amounts of the aqueous stock Dex-75 and PEG-8000 (or Ucon 50-HB-5100) solutions into a $1.2-\mathrm{mL}$ microtube using a Hamilton (Reno, NV, USA) ML-4000 four-probe liquid-handling workstation. Appropriate amounts of stock buffer 
Table 1

Phase compositions for dextran75-PEG-8000 and dextran75-Ucon 50-HB-5100 two-phase systems

\begin{tabular}{|c|c|c|c|c|c|c|c|c|}
\hline \multirow[t]{2}{*}{ System } & \multicolumn{2}{|l|}{ Total composition } & \multicolumn{3}{|l|}{ Top phase } & \multicolumn{3}{|l|}{ Bottom phase } \\
\hline & Dextran, \%(w/w) & PEG, \%(w/w) & Dextran, \%(w/w) & PEG, \%(w/w) & $\mathrm{NaPB}, \mathrm{M}$ & Dextran, \%(w/w) & PEG, \%(w/w) & NaPB, M \\
\hline \multicolumn{9}{|c|}{ Dextran75-PEG-8000-0.15 M NaCl-0.01 M sodium phosphate buffer (NaPB), pH 7.4 } \\
\hline I & 12.41 & 6.06 & 0.31 & 13.02 & 0.0048 & 22.44 & 0.53 & 0.0125 \\
\hline II & 10.75 & 5.22 & 0.48 & 11.21 & 0.0059 & 19.23 & 0.57 & 0.013 \\
\hline \multirow[t]{3}{*}{ III } & 8.99 & 4.34 & 1.21 & 9.12 & 0.0065 & 15.21 & 1.11 & 0.0114 \\
\hline & 8.42 & 4.08 & 1.64 & 8.05 & 0.0069 & 13.67 & 1.32 & 0.0111 \\
\hline & 7.85 & 3.82 & 2.15 & 7.28 & 0.007 & 11.66 & 2 & 0.0106 \\
\hline DP & 7.29 & 3.57 & & & & & & \\
\hline \multicolumn{9}{|c|}{$\mathrm{TLS}=-0.566 \pm 0.007$} \\
\hline \multirow[t]{2}{*}{ System } & \multicolumn{2}{|l|}{ Total composition } & \multicolumn{3}{|l|}{ Top phase } & \multicolumn{3}{|l|}{ Bottom phase } \\
\hline & Dextran, \%(w/w) & Ucon, \%(w/w) & Dextran, \%(w/w) & Ucon, \%(w/w) & $\mathrm{NaPB}, \mathrm{M}$ & Dextran, \%(w/w) & Ucon, \%(w/w) & $\mathrm{NaPB}, \mathrm{M}$ \\
\hline \multicolumn{9}{|c|}{ Dextran75-Ucon 50-HB-5100-0.15 M NaCl-0.01 M sodium phosphate buffer (NaPB), pH 7.4 } \\
\hline IV & 12.39 & 10.08 & 0.16 & 18.30 & 0.0032 & 26.51 & 0.59 & 0.0132 \\
\hline V & 10.42 & 8.41 & 0.18 & 15.52 & 0.0039 & 21.59 & 0.65 & 0.0124 \\
\hline \multirow[t]{3}{*}{ VI } & 8.23 & 6.82 & 0.37 & 12.17 & 0.0051 & 16.74 & 1.03 & 0.0127 \\
\hline & 7.57 & 6.25 & 0.60 & 11.00 & 0.0057 & 15.01 & 1.18 & 0.0109 \\
\hline & 6.90 & 5.73 & 1.05 & 9.74 & 0.0063 & 13.14 & 1.45 & 0.0106 \\
\hline \multirow[t]{2}{*}{ DP } & 5.30 & 4.60 & & & & & & \\
\hline & & & & $-0.682 \pm 0.008$ & & & & \\
\hline
\end{tabular}

Total ionic composition: $0.15 \mathrm{M} \mathrm{NaCl}$ in $0.01 \mathrm{M}$ sodium phosphate buffer, pH 7.4; DP, disruption point; TLS, tie-line slope.

solutions were added to give the required ionic and polymer composition of the final system with total volume of $0.5 \mathrm{~mL}$. All twophase systems had the polymer compositions indicated in Table 1 and the same salt composition of $0.15 \mathrm{M} \mathrm{NaCl}$ in $0.01 \mathrm{M}$ sodium phosphate buffer (NaPB), pH 7.4.

2.2.2.2. Partitioning experiments. An automated instrument for performing aqueous two-phase partitioning, Automated Signature Workstation-ASW (Analiza, Cleveland, OH, USA), was used for the partition experiments. The ASW system is based on the liquidhandling workstation ML-4000 (Hamilton) integrated with a FL600 fluorescence microplate reader (Bio-Tek Instruments, Winooski, VT, USA) and a UV-vis microplate spectrophotometer (SpectraMax Plus ${ }^{384}$; Molecular Devices, Sunnyvale, CA, USA). Solutions of all compounds (proteins, peptides, amino acids, and carbohydrates) were prepared in water at concentrations of $1-5 \mathrm{mg} / \mathrm{mL}$. Varied amounts $(0,15,30,45,60$, and $75 \mu \mathrm{L})$ of a given compound solution and the corresponding amounts $(100,85,70,55,40$ and $25 \mu \mathrm{L}$ ) of water were added to a set of the same polymer/buffer mixtures. The systems were vortexed in a multi-pulse vortexer and centrifuged for $30 \mathrm{~min}$ at $3000 \times \mathrm{g}$ in a refrigerated centrifuge (Jouan, BR4i, Thermo Fisher Scientific, Waltham, MA, USA) to hasten phase settling. The upper phase in each system was removed, the interface discarded, and aliquots of $20-70 \mu \mathrm{L}$ from the upper and lower phases were withdrawn in duplicate for analysis. Protein, peptides and tryptophan samples were combined with $250 \mu \mathrm{L}$ of $o$ phthaldialdehyde reagent solution (complete) in microplate wells. After moderate shaking for $2 \mathrm{~min}$ at room temperature fluorescence was determined with a fluorescence plate reader with a $360-\mathrm{nm}$ excitation filter and a 460-nm emission filter, and with a 100-125 sensitivity setting. Aliquots from both phases in the partition experiments with DNP-amino acids and NP-carbohydrates were diluted with water up to $320 \mu \mathrm{L}$ in microplate wells. Following moderate shaking for $20 \mathrm{~min}$ in an incubator (Vortemp 56EVC, Labnet International, Edison, NJ, USA) at room temperature $\left(23^{\circ} \mathrm{C}\right)$, optical absorbance was measured at $362 \mathrm{~nm}$ and $302 \mathrm{~nm}$ for DNP-amino acids and carbohydrates, respectively with a UV-vis plate reader. In all measurements the correspondingly diluted pure phases were used as blank solutions. The distribution coefficient, $K$, is defined as the ratio of the sample concentration in the PEG-rich or Uconrich (upper) phase to the sample concentration in the dextran-rich (lower) phase. The $K$-value for each solute was determined as the slope of the concentration in the upper phase plotted as a function of the concentration in the bottom phase averaged over the results obtained from two to four partition experiments carried out at the specified ionic composition of the system $(0.15 \mathrm{M} \mathrm{NaCl}$ in $0.01 \mathrm{M}$ $\mathrm{NaPB}, \mathrm{pH}$ 7.4). The deviation from the average $K$-value was always less than $5 \%$, and in most cases lower than $2 \%$.

\section{Results and discussion}

\subsection{Phase diagrams}

Fig. 1 presents phase diagrams of both Dex-75-PEG-8000 and Dex-75-Ucon 50-HB-5100 two-phase systems. The corresponding polymer compositions are given in Table 1 . In this Table numbers I-VI correspond to the systems used for partitioning experiments. It can be seen from comparison of the phase diagrams in Fig. 1 that while the binodal curves for both ATPSs are so close that they almost coincide, the slopes of the tie-lines are constant, systemspecific, and very different for the two systems. Albertsson was the

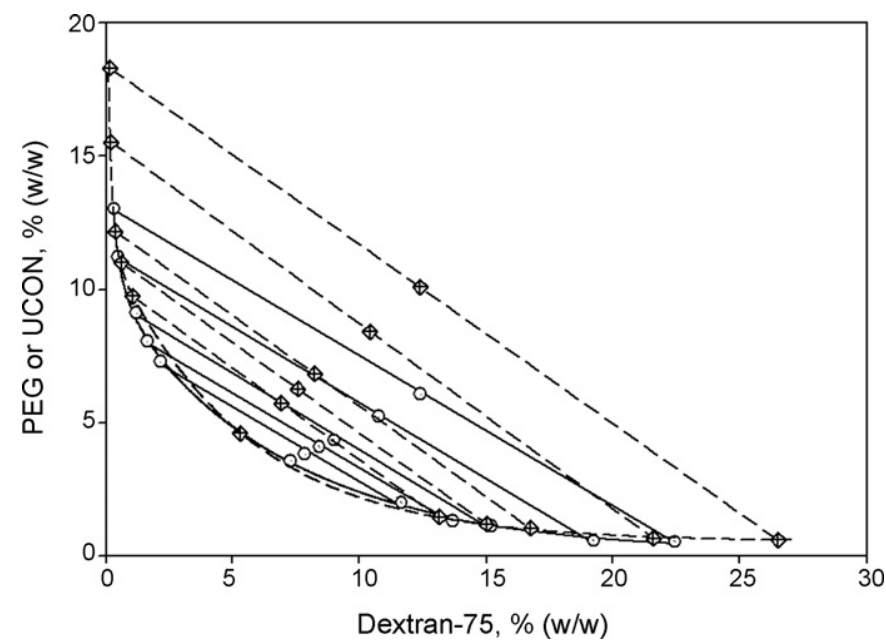

Fig. 1. Phase diagrams of Dex-75-PEG-8000 (-) and Dex-75-Ucon 50-HB-5100 (---) ATPSs at $23^{\circ} \mathrm{C}$. 


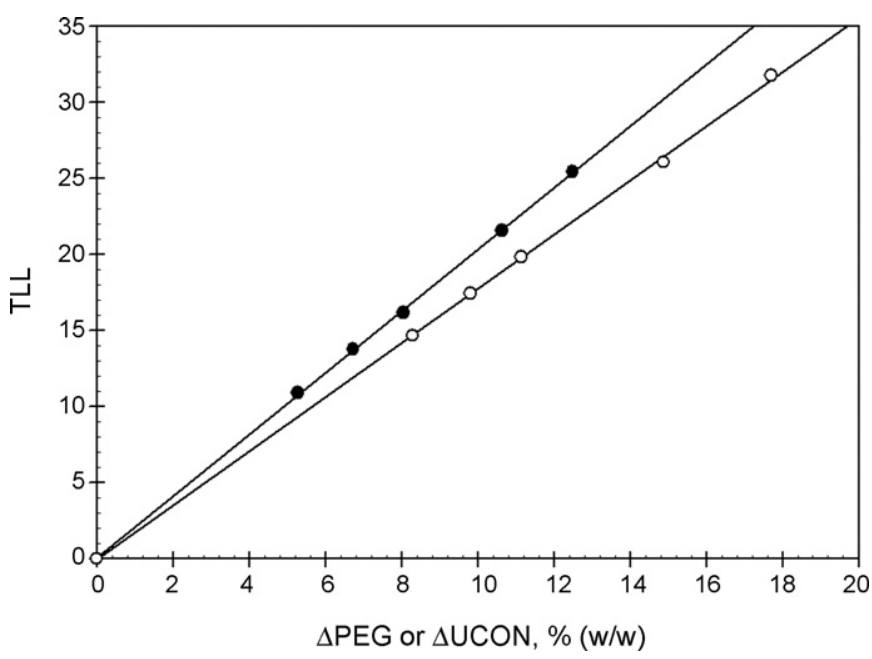

Fig. 2. Tie-line length (TLL) in aqueous dextran-PEG and dextran-Ucon two-phase systems as a function of $\Delta P$. $\Delta$ denotes the difference between the polymer weight fractions $(P)$ in the coexisting phases. P is PEG $(\bullet)$ or Ucon $(\bigcirc)$.

first to report that while the tie-line slope (TLS) is usually constant for a given ATPS there are exceptions [1].

The tie-line slope "TLS" is defined as

$\mathrm{TLS}=\frac{\Delta P_{1}}{\Delta P_{2}}$

where $\Delta P_{1}$ and $\Delta P_{2}$ are the differences between the polymer weight fractions in the coexisting phases, where 1 stands for the polymer rich in the upper phase (in the present case PEG or Ucon) and 2 for the polymer rich in the bottom phase (in the present case
Dex). Taking into account that the tie-line length (TLL) is defined as

$\mathrm{TLL}=\left[\left(\Delta P_{1}\right)^{2}+\left(\Delta P_{2}\right)^{2}\right]^{1 / 2}$

where the symbols have the same meaning as above and combining Eqs. (1) and (2) we can obtain the following linear relationship:

$\mathrm{TLL}=\left[1+\left(\frac{1}{\mathrm{TLS}}\right)^{2}\right]^{1 / 2} \Delta P_{1}$

Eq. (3) is a simple way to confirm/reject the assumption of the TLS being constant. The experimental data are plotted in Fig. 2 and the slopes of both experimentally observed linear curves in the graph are $2.026 \pm 0.015$ for Dex-PEG system and $1.780 \pm 0.017$ for Dex-Ucon system. These values agree very well with those calculated from the above equation (using the experimentally obtained values of TLS, for each system-see Table 1)-2.030 and 1.775, respectively.

\subsection{Partitioning of solutes at different polymer concentrations within a given ATPS}

Partition coefficients for all the solutes examined in the present work in ATPSs of different polymer composition and polymer concentrations are listed in Table 2. Fig. 3 presents the logarithms of the distribution coefficients (defined as concentration in the top phase divided by concentration in the bottom phase) for solutes examined in systems I, II and III (Dex-PEG system with different polymer concentrations) as a function of the TLL. Similar data obtained for the aqueous Dex-Ucon two-phase system (systems IV, V and VI) are presented in Fig. 4. All the experimentally observed curves are essentially linear, in agreement with earlier observations in the literature ([4] pp. 181-184; 11). These experimental data may be

Table 2

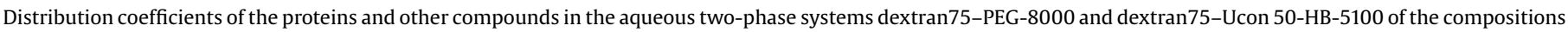
indicated

\begin{tabular}{|c|c|c|c|c|c|c|}
\hline \multirow[t]{2}{*}{ Solute } & \multicolumn{6}{|c|}{ Partition coefficient, $K^{\mathrm{a}}$} \\
\hline & System I ${ }^{\mathrm{b}}$ & System II $^{\mathrm{b}}$ & System III ${ }^{\mathrm{b}}$ & System IV & System $\mathrm{V}^{\mathrm{c}}$ & System VI ${ }^{\mathrm{c}}$ \\
\hline RNAse A & 0.489 & 0.559 & 0.686 & 0.247 & 0.355 & 0.537 \\
\hline RNAse B & 0.455 & & & 0.265 & & \\
\hline Chymotrypsinogen & 2.71 & & & 1.78 & & \\
\hline Trypsinogen & 0.89 & & & 0.702 & & \\
\hline Lysozyme & 2.36 & 1.68 & 1.46 & 2.95 & 2.69 & 2.20 \\
\hline Hb bovine & 0.074 & & & 0.053 & & \\
\hline Hb human & 0.131 & & & 0.117 & & \\
\hline Lactoglobulin & 0.071 & 0.119 & 0.2445 & 0.033 & 0.037 & 0.115 \\
\hline Transferrin & 0.0084 & & & 0.0015 & 0.0039 & 0.0279 \\
\hline Myoglobin & 0.161 & 0.251 & 0.379 & 0.080 & 0.136 & 0.250 \\
\hline Bovine $\gamma$-globulin & 0.024 & & & 0.007 & & \\
\hline Human $\gamma$-globulin & 0.043 & & & 0.014 & & \\
\hline Cytochrome $c$ & 0.29 & & & 0.12 & & \\
\hline Lipase & 0.716 & 0.733 & 0.773 & 0.658 & 0.649 & 0.761 \\
\hline DNP-Gly & 0.873 & 0.905 & 0.944 & 1.018 & 1.127 & 1.072 \\
\hline DNP-Ala & 0.985 & & & 1.326 & & \\
\hline DNP-NVal & 1.085 & & & 1.654 & & \\
\hline DNP-NLeu & 1.164 & 1.108 & 1.088 & 2.046 & 1.795 & 1.513 \\
\hline DNP-AO* & 1.348 & & & 3.496 & & \\
\hline $\operatorname{Trp}$ & 0.980 & & & 1.011 & & \\
\hline Di-Trp & 1.714 & & & 2.816 & & \\
\hline Tri-Trp & 3.981 & & & 24.35 & & \\
\hline Fucopyranoside** & 1.307 & & & 1.552 & & \\
\hline Galactopyranoside ${ }^{* *}$ & 1.184 & & & 1.403 & & \\
\hline$\beta$-Glucopyranoside** & 1.268 & & & 1.538 & & \\
\hline$\alpha$-Glucopyranoside ${ }^{* *}$ & 1.231 & & & 1.587 & & \\
\hline$\alpha$-Mannopyranoside** & 1.175 & & & 1.597 & & \\
\hline
\end{tabular}

*Dinitrophenyl-amino-octanoic acid and ${ }^{* *} p$-nitophenyl-derivatives of carbohydrates indicated.

a Experimental error in each $K$-value always less than 5\%, and in most cases less than $2 \%$

b System I composition: 12.41\% Dex; 6.06\% PEG, system II composition: 10.75\% Dex; 5.22\% PEG and system III composition: 8.99\% Dex; 4.34\% PEG.

c System IV composition: 12.39\% Dex; 10.08\% Ucon, system V composition: 10.42\% Dex; 8.41\% Ucon and system IV composition: 8.23\% Dex; 6.82\% Ucon. 


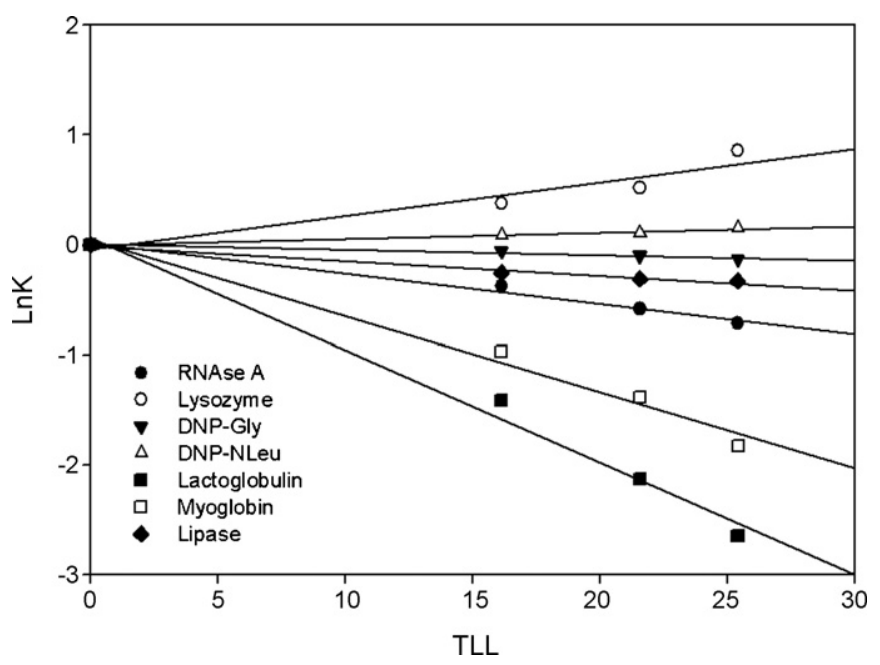

Fig. 3. Logarithms of distribution coefficients for several solutes examined in aqueous Dex-PEG system with different polymer concentrations (systems I, II and III, Table 1) as functions of the TLL.

generally described as

$\ln K_{j}=\alpha_{j i} \mathrm{TLL}$

where $\alpha_{j i}$ is a constant characterizing the effect of the tie-line length of a given system on the distribution coefficient $K_{j}$ of the solute $j$ in that system.

For two different tie-lines, within a given ATPS, it follows from Eq. (4) that:

$\ln K_{j}^{1}=\left(\frac{\mathrm{TLL}^{1}}{\mathrm{TLL}^{2}}\right) \ln K_{j}^{2}$

where the superscripts refer to different tie-lines ( 1 and 2 ) of the same ATPS and the other symbols have the same meaning as above. Fig. 5 depicts a plot of experimental $\ln K$ data versus the calculated values based on Eq. (4a) for solutes partitioned in the ATPSs studied in the present work as well as for those found in the literature (see Table 3). The results plotted in Fig. 5 may be expressed by

$\ln K_{\text {calc }}=0.02( \pm 0.02)+0.99( \pm 0.015) \ln K_{\text {exp }}$,

$N=45 ; r^{2}=0.9855$,

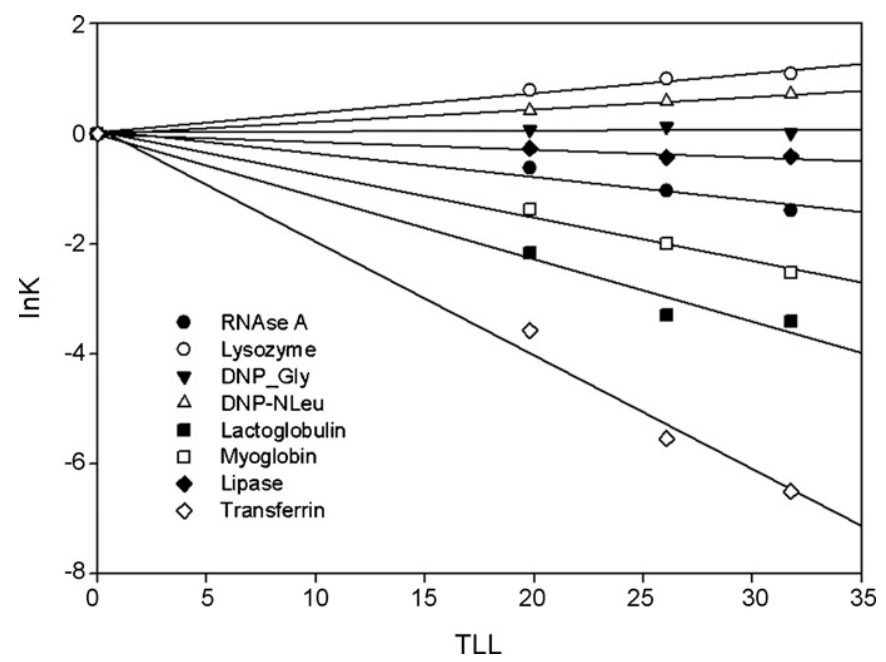

Fig. 4. Logarithms of distribution coefficients for several solutes examined in aqueous Dex-Ucon system with different polymer concentrations (systems IV, V and VI, Table 1) as functions of the TLL.

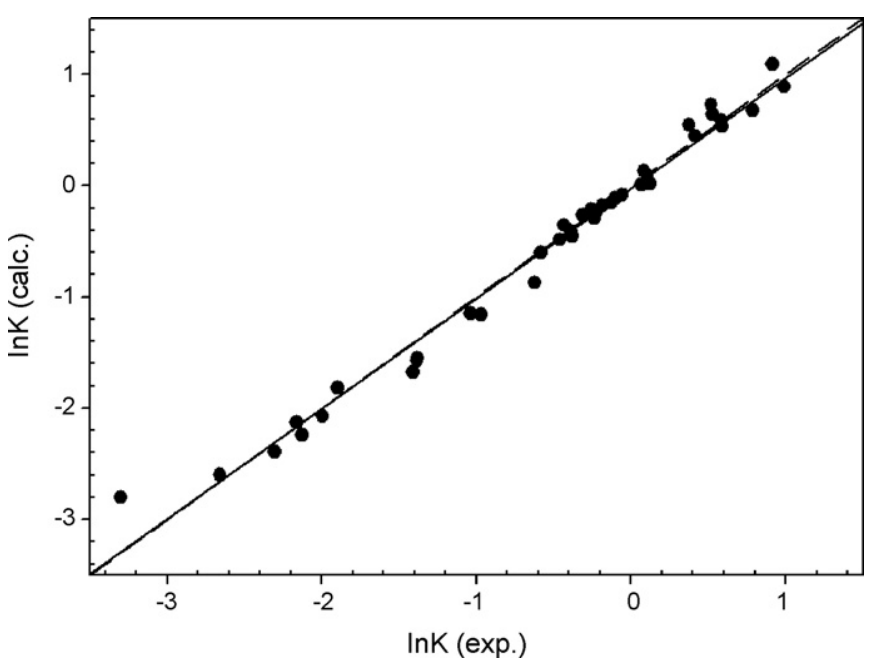

Fig. 5. Comparison of experimental $\ln K$ data and predicted values based on Eq. (4a). The data is from the present work and from the literature [27-29]. Theoretical (-) and experimental (- -) lines.

where $K_{\text {calc }}$ is the partition coefficient calculated according to Eq. (4a), $K_{\text {exp }}$ is the experimental partition coefficient, $N$ is the number of solutes, and $r^{2}$ is the correlation coefficient.

Eq. (4a) may be considered as a simplified version of the solvent regression equation (so-called Collander equation [26]):

$\ln K_{i}=a_{i j} \ln K_{j}+b_{i j}$

where $K_{i}$ and $K_{j}$ are partition coefficients for any given solute in the $i$-th and $j$-th two-phase systems; $a_{i j}$ and $b_{i j}$ are constants, the values of which depend upon the particular composition of the $i$-th and $j$-th two-phase systems under comparison. For a given ATPS at different polymer concentrations corresponding to different tie-lines the intercept in the Collander equation should be equal to zero in agreement with the experimental data reported in Table 3.

Analysis of the data from the literature confirms the results presented here suggesting that the general linear relationship between the logarithms of the distribution coefficients in different systems holds for any ATPS. The parameters for these equations are listed in Table 4.

\subsection{Partitioning of solutes in ATPSs formed by different components}

Analysis of the $\alpha_{j i}$ values found for all the solutes in the aqueous Dex-PEG and Dex-Ucon two-phase systems indicate that the $\alpha_{j i}$ values observed in the two ATPSs under consideration are linearly correlated. This relationship may be described as

$$
\begin{aligned}
& \alpha_{j i}^{\text {Dex-Ucon }}=0.004( \pm 0.004)+1.18( \pm 0.08) \alpha_{j i}^{\text {Dex-PEG }}, \\
& N=7 ; r^{2}=0.9782,
\end{aligned}
$$

where $N$ is the number of solutes, and $r^{2}$ is the correlation coefficient.

The correlation described by Eq. (7) suggests that the distribution coefficients for the solutes examined in the two different ATPSs are also correlated according to the Collander linear equation (Eq. (6) above):

Fig. 6 presents the logarithms of distribution coefficients for all the solutes examined in Dex-Ucon system (system IV, Table 1) plotted against logarithms of distribution coefficients of the same solutes in Dex-PEG system (system I, Table 1). There is a linear 
Table 3

Comparison of equation coefficients in two different tie-lines within a given ATPS indicated as calculated from the data reported here as well as from the literature

\begin{tabular}{|c|c|c|c|c|c|c|c|c|}
\hline \multicolumn{2}{|l|}{ System "I" } & \multicolumn{2}{|l|}{ System “0” } & \multirow[t]{2}{*}{ Coefficient $a$} & \multirow[t]{2}{*}{ Coefficient $b$} & \multirow[t]{2}{*}{$N$} & \multirow[t]{2}{*}{$r^{2}$} & \multirow[t]{2}{*}{ References } \\
\hline Dex-75 & PEG-8000 & Dex-75 & PEG-8000 & & & & & \\
\hline \multicolumn{2}{|c|}{ System III from Table 1} & \multicolumn{2}{|c|}{ System I from Table 1} & $0.520 \pm 0.005$ & $-0.022 \pm 0.009$ & 7 & 0.9959 & Present work \\
\hline Dex-75 & PEG-8000 & Dex-75 & PEG-8000 & & & & & \\
\hline \multicolumn{2}{|c|}{ System II from Table 1} & \multicolumn{2}{|c|}{ System I from Table 1} & $0.762 \pm 0.007$ & $-0.05 \pm 0.01$ & 7 & 0.9961 & Present work \\
\hline Dex-75 & Ucon 50-HB-5100 & Dex-75 & Ucon 50-HB-5100 & & & & & \\
\hline \multicolumn{2}{|c|}{ System VI from Table 1} & \multicolumn{2}{|c|}{ System IV from Table 1} & $0.58 \pm 0.01$ & $0.04 \pm 0.03$ & 8 & 0.9925 & Present work \\
\hline Dex-75 & Ucon 50-HB-5100 & Dex-75 & Ucon 50-HB-5100 & & & & & \\
\hline \multicolumn{2}{|c|}{ System $\mathrm{V}$ from Table 1} & \multicolumn{2}{|c|}{ System IV from Table 1} & $0.87 \pm 0.02$ & $0.02 \pm 0.04$ & 8 & 0.9942 & Present work \\
\hline Dex-40 & PEG-4000 & Dex-40 & PEG-4000 & & & & & \\
\hline $7.00 \%$ & $10.02 \%$ & $7.50 \%$ & $10.50 \%$ & $0.87 \pm 0.02$ & $-0.03 \pm 0.02$ & 10 & 0.9976 & {$[27,28]^{\mathrm{a}}$} \\
\hline Dex-500 & EO30PO70 & Dex-500 & EO30PO70 & & & & & \\
\hline $7.1 \%$ & $6.8 \%$ & $9.0 \%$ & $9.0 \%$ & $0.62 \pm 0.03$ & $-0.03 \pm 0.01$ & 27 & 0.9590 & {$[8]^{\mathrm{b}}$} \\
\hline Dex-500 & Ucon 50-HB-5100 & Dex-500 & Ucon 50-HB-5100 & & & & & \\
\hline $5.1 \%$ & $4.4 \%$ & $9.2 \%$ & $4.6 \%$ & $0.59 \pm 0.06$ & $0.05 \pm 0.06$ & 5 & 0.9576 & {$[29]^{c}$} \\
\hline PEG-8000 & K-phosphate buffer & PEG-8000 & K-phosphate buffer & & & & & \\
\hline \multicolumn{2}{|c|}{$\Delta P E G^{\mathrm{d}}=0.171 \%$} & \multicolumn{2}{|c|}{$\Delta P E G^{\mathrm{d}}=0.257 \%$} & $0.71 \pm 0.02$ & $-0.01 \pm 0.05$ & 11 & 0.9908 & {$[30]^{\mathrm{d}}$} \\
\hline PEG-8000 & $\mathrm{MgSO}_{4}$ & PEG-8000 & $\mathrm{MgSO}_{4}$ & & & & & \\
\hline $0.109 \%$ & $0.60 \mathrm{M}$ & $0.101 \%$ & $1.40 \mathrm{M}$ & $0.341 \pm 0.008$ & $0.04 \pm 0.01$ & 66 & 0.9689 & {$[31]^{\mathrm{e}}$} \\
\hline
\end{tabular}

$\ln K_{i}=a \ln K_{0}+b ; r^{2}$, correlation coefficient; $N$, number of solutes examined (all polymer concentrations in wt.\%); ionic composition and type of solutes partitioned.

a No salt additives used; solutes: amino acids; peptides; proteins.

b $0.05 \mathrm{M} \mathrm{K}_{2} \mathrm{SO}_{4}$ in $0.005 \mathrm{M}$ sodium phosphate buffer, $\mathrm{pH} 7.0$; solutes: proteins, 7 (outlier, ribonuclease $\mathrm{A}$ ) and amino acids (20).

c $0.01 \mathrm{M}$ sodium acetate buffer, $\mathrm{pH} 5.0$; solutes: peptides, proteins.

d Composition of the systems not reported explicitly; $\mathrm{pH} \sim 5.5 ; \triangle \mathrm{PEG}$ indicated, reported difference between PEG concentrations in the coexisting phases; solutes: proteins (3); peptides (6); amino acid; ethanol.

e Solutes: di- and tri-peptides (37), amino acids (14), and organic nonionic compounds (15).

correlation between distribution coefficients of all the proteins examined in the two systems under study:

$\ln K_{j}^{\text {Dex-Ucon }}=-0.23( \pm 0.12)+1.240( \pm 0.054) \ln K_{j}^{\text {Dex-PEG }}$,

$N=14 ; r^{2}=0.9780$,

where $K_{j}^{\text {Dex-Ucon }}$ is the distribution coefficient of protein $j$ in Dex-Ucon system (system IV, Table 1 ), $K_{j}^{\text {Dex-Ucon }}$ is the distribution coefficient of protein $j$ in Dex-PEG system (system I, Table 1$), N$ is the number of proteins; $r^{2}$ is the correlation coefficient.

Similar correlation was previously observed for the partitioning of different solutes (amino acids, glycosides, nucleotides, proteins and nucleic acids) in the system Dex-PEG and Dex-Ficoll ([4], pp. 270-276). It was concluded [4] that the correlation implies either that the solute-phase polymer interactions are identical for all the different solutes examined, or that the solute-polymer interactions do not occur and/or do not affect the solute partitioning in these systems. The last assumption appears to be more plausible due to purely probabilistic reasons. Thus, the major conclusions from the above Eq. (8) are that: (i) the proteins randomly selected for analysis in this study do not interact with the phase-forming polymers; and (ii) the distribution coefficient for any protein determined in one of the two systems may be used to predict the distribution coefficient for the same protein in the other system.

The data plotted in Fig. 6 indicate also that there is a correlation for the distribution coefficients of examined DNP-amino acids different from the one described by Eq. (8), and a different one for the homooligopeptides of tryptophan (tryptophan, di-tryptophan and tri-tryptophan). We did not examine these correlations because of the limited number of compounds examined in each series. There seems to be no correlation for the distribution coefficients of nitrophenylated monosaccharides. The lack of correlation between the distribution coefficients for monosaccharides may be because all the $K$-values for these compounds are very close to unity in both systems.

It has been previously suggested ([4], pp. 270-276) that the physical meaning of the slope of Eq. (8) (coefficient $a$ in Eq. (6)) is the ratio of the differences between the hydrophobic characters of the coexisting phases in the ATPSs under comparison, while the intercept in Eq. (8) (coefficient $b$ in Eq. (6)) represents the difference between the polar and electrostatic interactions of the solutes with the aqueous media in the coexisting phases in the systems under comparison. The data obtained for DNP-amino acids were used to estimate these parameters, as described in detail in ([4], pp.162-196). The experimental data obtained for DNP-amino acids are plotted in Fig. 7, and the linear trends observed may be

Table 4

Comparison of equation coefficients for different ATPSs indicated as calculated from the data reported here as well from the literature

\begin{tabular}{|c|c|c|c|c|c|c|c|c|}
\hline \multicolumn{2}{|c|}{ System "I" } & \multicolumn{2}{|l|}{ System “0” } & \multirow[t]{2}{*}{ Coefficient $a$} & \multirow[t]{2}{*}{ Coefficient $b$} & \multirow[t]{2}{*}{$N$} & \multirow[t]{2}{*}{$r^{2}$} & \multirow[t]{2}{*}{ References } \\
\hline Dex-75 & Ucon 50-HB-5100 & Dex-75 & PEG-8000 & & & & & \\
\hline \multicolumn{2}{|c|}{ System IV from Table 1} & \multicolumn{2}{|c|}{ System I from Table 1} & $1.24 \pm 0.05$ & $-0.2 \pm 0.1$ & 14 & 0.9780 & Present work \\
\hline Dex-40 & PEG-8000 & Dex-70 & PEG-8000 & & & & & \\
\hline $8.0 \%$ & $6.0 \%$ & $8.0 \%$ & $6.0 \%$ & $0.99 \pm 0.08$ & $-0.3 \pm 0.2$ & 9 & 0.9571 & {$[32]^{\mathrm{a}}$} \\
\hline Dex-70 & PEG-8000 & Dex-220 & PEG-8000 & & & & & \\
\hline $8.0 \%$ & $6.0 \%$ & $8.0 \%$ & $6.0 \%$ & $0.9 \pm 0.1$ & $-0.7 \pm 0.2$ & 8 & 0.9118 & {$[32]^{\mathrm{a}}$} \\
\hline Dex-220 & PEG-8000 & Dex-500 & PEG-8000 & & & & & \\
\hline $8.0 \%$ & $6.0 \%$ & $8.0 \%$ & $6.0 \%$ & $1.10 \pm 0.07$ & $-0.2 \pm 0.1$ & 8 & 0.9592 & {$[32]^{a}$} \\
\hline Dex-500 & PEG-8000 & Dex-2000 & PEG-8000 & & & & & \\
\hline $8.0 \%$ & $6.0 \%$ & $8.0 \%$ & $6.0 \%$ & $0.86 \pm 0.07$ & $-0.4 \pm 0.1$ & 9 & 0.9598 & {$[32]^{a}$} \\
\hline
\end{tabular}

$\ln K_{i}=a \ln K_{0}+b ; r^{2}$, correlation coefficient; $N$, number of solutes examined (all polymer concentrations in wt.\%); ionic composition and type of solutes partitioned.

a $0.01 \mathrm{M}$ sodium phosphate buffer, $\mathrm{pH}$ 6.8; solutes: proteins. 


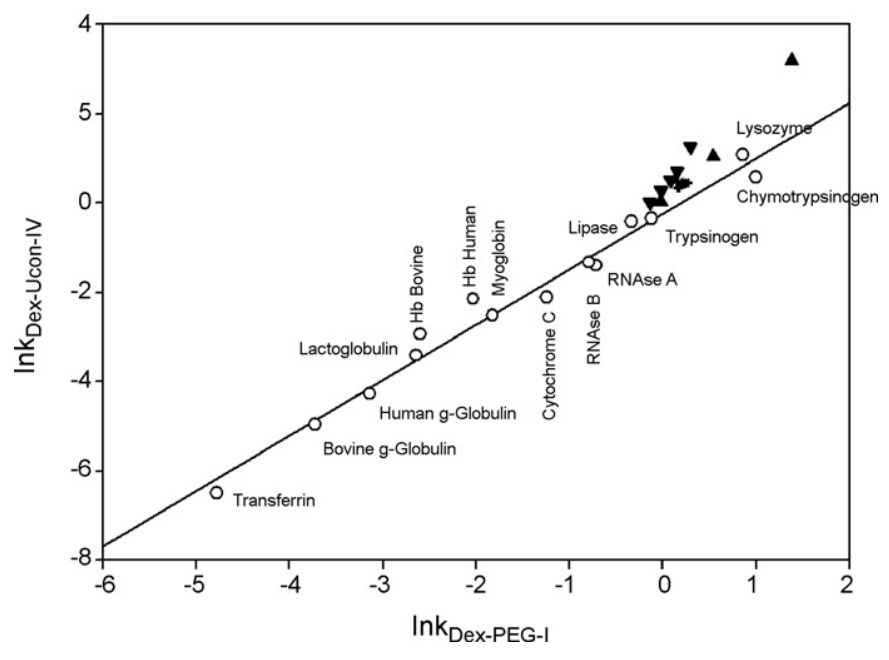

Fig. 6. Logarithms of distribution coefficients for different solutes $(\bigcirc$, proteins; $\mathbf{\nabla}$, DNP-amino acids; $\boldsymbol{\Delta}$, tryptophan, di-tryptophan and tri-tryptophan; and +, NPmonossacharides) examined in system IV (Dex-Ucon system, Table 1) plotted against logarithms of distribution coefficients of the same solutes in system I (Dex-PEG system, Table 1 ).

described as

$\ln K_{\mathrm{DNP}-\mathrm{AA}}=C+E N_{\mathrm{C}}$

where $K_{\text {DNP-AA }}$ is the distribution coefficient of a DNP-amino acid with aliphatic side-chain; $N_{C}$ is equivalent number of $\mathrm{CH}_{2}$ groups in the aliphatic side-chain of a given DNP-amino acid; $E$ is an average $\ln K$ increment per $\mathrm{CH}_{2}$ group; $\mathrm{C}$ represents the total contribution of the non-alkyl part of the structure of a DNP-amino acid into $\ln K$. The coefficient $E$ values are $0.196 \pm 0.005$ in Dex-Ucon system IV and $0.068 \pm 0.004$ in the Dex-PEG system I, while coefficient $C$ values are $0.004 \pm 0.017$ in Dex-Ucon system IV and $-0.116 \pm 0.016$ in the Dex-PEG system I. The difference between the hydrophobic character of the coexisting phases in the Dex-Ucon system being almost three times larger than that in the Dex-PEG system seems intuitively reasonable, since Ucon should be more hydrophobic than PEG due to the presence of propylene oxide monomers in its structure, and hence should have a more pronounced effect on the properties of the aqueous media in the corresponding phase of a given ATPS.

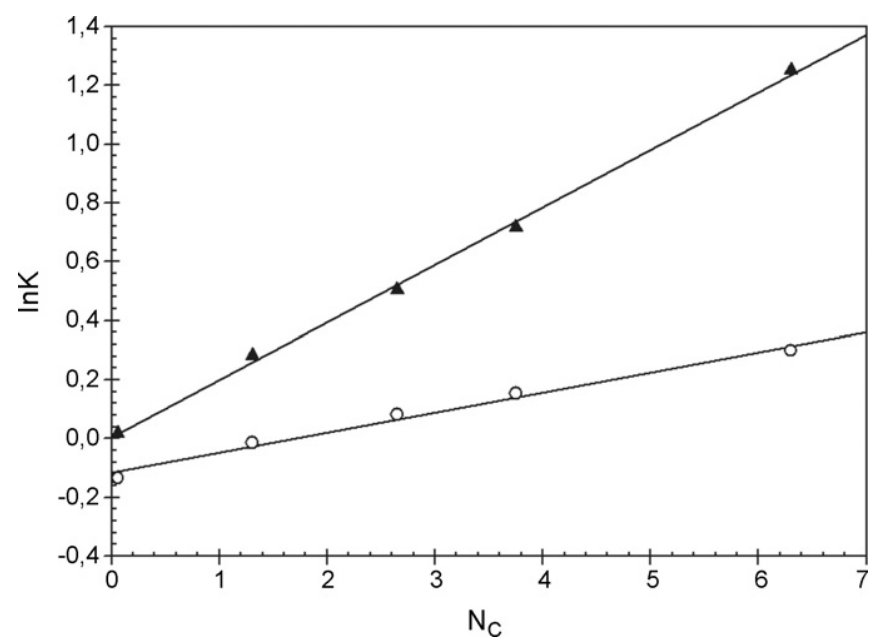

Fig. 7. Distribution coefficients of sodium salts of DNP-amino acids with aliphatic side-chains as functions of side-chain length. $\bigcirc$. Dex-PEG system I; $\mathbf{\Delta}$, Dex-Ucon system IV.
Since distribution coefficients of homologous series of compounds in two different two-phase systems are described by Eq. (9) (with different $E$ and $C$ values depending on the particular twophase systems under comparison), and $N_{C}$ for any given DNP-amino acid is constant, it follows that:

$\ln K_{\mathrm{DNP}-\mathrm{AA}}^{\mathrm{I}}=a \ln K_{\mathrm{DNP}-\mathrm{AA}}^{\mathrm{II}}+b=\left(\frac{E^{\mathrm{I}}}{E^{\mathrm{II}}}\right) \ln K_{\mathrm{DNP}-\mathrm{AA}}^{\mathrm{II}}+C^{\mathrm{I}}-\left(\frac{E^{\mathrm{I}}}{E^{\mathrm{II}}}\right) C^{\mathrm{II}}$

where superscripts I and II denote two different two-phase systems under comparison.

It clearly follows from Eq. (10) that coefficient $a=\left(E^{\mathrm{I}} / E^{\mathrm{II}}\right)$, and coefficient $b=C^{\mathrm{I}}-\left(E^{\mathrm{I}} / E^{\mathrm{II}}\right) C^{\mathrm{II}}$. From the data obtained in this study it is clear that the value of coefficient $a$ in Eq. (8) does not agree with the one estimated from the analysis of the distribution coefficients of DNP-amino acids. It also follows from the different slopes of the correlation between $K$-values for the proteins and for DNPamino acids in the two ATPSs under comparison (see in Fig. 6). This fact seems to indicate that the previous assumption [4] was incorrect, and that dividing all the solute-solvent interactions in aqueous two-phase systems into just hydrophobic (parameter a) and polar (parameter b) interactions is oversimplification.

The major conclusion presented here, particularly that proteins do not interact with the phase-forming polymers, is at this stage only valid for a limited set of systems. Unfortunately, there are very few studies of the same proteins partitioned in ATPSs formed by polymers of different chemical nature, and even then the purity and other characteristics of the protein preparations used by different authors may differ significantly. It should also be mentioned that the correlation observed here is valid only for ATPSs with the same ionic composition. Therefore it is early at this stage to draw any general conclusion in regard to the existence of a linear correlation between the logarithms of the distribution coefficients of different proteins in ATPSs formed by different polymers, and more experimental work is necessary. These issues will be explored further in our studies that are in progress.

\section{Conclusions}

Distribution coefficients for several solutes (proteins, peptides, amino acids, and carbohydrates) were measured in aqueous two-phase systems (ATPSs). Dextran-PEG and Dextran-Ucon 50HB-5100 (a random copolymer of ethylene glycol and propylene glycol) both containing $0.15 \mathrm{M} \mathrm{NaCl}$ in $0.01 \mathrm{M}$ phosphate buffer, $\mathrm{pH} 7.4$, at $23^{\circ} \mathrm{C}$. Distribution coefficients of some selected solutes were also measured in the above two-phase systems at three different polymer concentrations for each system. It was established that the distribution coefficients for all of the proteins examined in the ATPSs under study are interrelated according to the so-called Collander linear equation.

List of symbols

$a_{i j} \quad$ constant on the Collander equation

$b_{i j} \quad$ constant on the Collander equation

C contribution of the non-alkyl part of the structure of a DNP-amino acid into $\ln \mathrm{K}$

E average $\ln \mathrm{K}$ increment per $\mathrm{CH}_{2}$ group

$K \quad$ distribution coefficient

$N_{\mathrm{C}} \quad$ equivalent number of $\mathrm{CH}_{2}$ groups in the aliphatic sidechain of a given DNP-amino acid

$P_{i} \quad$ Concentration of polymer $i$ in weight fractions

$r^{2} \quad$ correlation coefficient

TLL tie-line length

TLS the tie-line slope 
Greek symbols

$\alpha \quad$ constant characterizing the effect of the tie-line length of a given system on the distribution coefficient

$\Delta \quad$ difference

\section{Acknowledgments}

Financial support for this work was in part provided by LSRE financing by FEDER/POCI2010 and by Project POCI/EQU/60720/2004 for which the authors are thankful. P.P.M. acknowledges the Ph.D. scholarship (SFRH/BD/18397/2004) from Fundação para a Ciência e a Tecnologia (FCT), Lisbon, Portugal.

\section{References}

[1] P.A. Albertsson, Partition of Cell Particles and Macromolecules, 3rd ed., Wiley, New York, 1986.

[2] H. Walter, D.E. Brooks, D. Fisher (Eds.), Partitioning in Aqueous Two-Phase Systems: Theory, Methods, Use, and Applications to Biotechnology, Academic Press, Orlando, FL, 1985.

[3] H. Walter, G. Johansson (Eds.), Methods in Enzymology, vol. 228, Academic Press, Orlando, FL, 1994

[4] B.Y. Zaslavsky, Aqueous Two-Phase Partitioning: Physical Chemistry and Bioanalytical Applications, Marcel Dekker, New York, 1994.

[5] H.D. Willauer, J.G. Huddleston, R.D. Rogers, Ind. Eng. Chem. Res. 41 (2002) 2591-2601.

[6] J. Persson, D.C. Andersen, P.M. Lester, Biotechnol. Bioeng. 90 (2005) 442-451.

[7] A. Frerix, P. Geilenkirchen, M. Muller, M.-R. Kula, Hubbuch, J. Biotechnol. Bioeng. 96 (2007) 57-66.

[8] K. Berggren, A. Wolf, J.A. Asenjo, B.A. Andrews, F. Tjerneld, Biochim. Biophys. Acta 1596 (2002) 253-268.

[9] A. Zaslavsky, N. Gulyaeva, A. Chait, B. Zaslavsky, Anal. Biochem. 296 (2001) 262-269.
[10] P. Jensen, T. Stigbrand, V.P. Shanbhag, J. Chromatogr. A 668 (1994) 101-106

[11] P.J. Flory, Principles of Polymer Chemistry, Cornell University Press, Ithaca, New York, 1953.

[12] A. Sjoeberg, G. Karlstroem, Macromolecules 22 (3) (1989) 1325-1330.

[13] C.H. Kang, S.I. Sandler, Fluid Phase Equilib. 38 (1987) 245-272.

[14] C.H. Kang, S.I. Sandler, Biotechnol. Bioeng. 32 (1988) 1158-1164.

[15] E. Edmond, A.G. Ogston, Biochem. J. 109 (1968) 569-576.

[16] R.S. King, H.W. Blanch, J.M. Prausnitz, AIChE J. 34 (1988) 1585-1594

[17] D. Forciniti, C.K. Hall, M.-R. Kula, Fluid Phase Equilib. 61 (1991) 243-262.

[18] F. Doebert, A. Pfennig, M. Stumpf, Macromolecules 28 (1995) 7860-7868.

[19] M.L. Moody, H.D. Willauer, S.T. Griffin, J.G. Huddleston, R.D. Rogers, Ind. Eng. Chem. Res. 44 (2005) 3749-3760.

[20] H.D. Willauer, J.G. Huddleston, R.D. Rogers, Ind. Eng. Chem. Res. 41 (2002) 1892-1904.

[21] R.D. Rogers, H.D. Willauer, S.T. Griffin, J.G. Huddleston, J. Chromatogr. B 711 (1998) 255-263.

[22] H.D. Willauer, J.G. Huddleston, S.T. Griffin, R.D. Rogers, Sep. Sci. Technol. 34 (1999) 1069-1090.

[23] A.R. Katrizky, K. Tamm, M. Kuanar, D.C. Fara, A. Oliferenko, P. Oliferenko, J.G. Huddleston, R.D. Rogers, J. Chem. Inf. Comput. Sci. 44 (2004) 136-142.

[24] C. Hansch, A. Leo, Exploring QSAR, Fundamentals and Applications in Chemistry and Biology, American Chemical Society, Washington, DC, 1995.

[25] L.S. Clesceri, A.E. Greenberg, A.D. Eaton (Eds.), Standard Methods for the Examination of Water and Wastewater, 20th ed., American Public Health Association, Baltimore, MD, 1998.

[26] R. Collander, Acta Physiol. Scand. 13 (1947) 363-381.

[27] K. Kakisaka, T. Shindou, T. Ishidao, Y. Iwai, Y. Azrai, J. Chem. Eng. Jpn. 31 (1998) 991-995.

[28] T. Furuya, Y. Iwai, Y. Tanaka, H. Uchida, S. Yamada, Y. Arai, Fluid Phase Equilib. 110 (1995) 115-128.

[29] M. Carlsson, K. Berggren, P. Linse, A. Veide, F. Tjerneld, J. Chromatogr. A 756 (1996) 107-117.

[30] M. Eiteman, C. Hassinen, A. Veide, Biotechnol. Prog. 10 (1994) 513-519.

[31] Eiteman, M., Ph.D. Dissertation, University of Virginia, Charlottesville, VA, 1991.

[32] P.A. Albertsson, A. Cajarville, D.E. Brooks, F. Tjerneld, Biochim. Biophys. Acta 926 (1987) 87-93. 